\title{
O MERCADO DE GALERIAS E O COMÉRCIO DE ARTE MODERNA: São Paulo e Rio de Janeiro nos anos 1950-1960
}

\author{
Maria Lúcia Bueno*
}

\begin{abstract}
Resumo: Os anos 50 no Brasil transitaram do Nacionalismo de Vargas ao Desenvolvimento de JK, passando pela implantação definitiva de uma sociedade urbana modernizada. Sintonizada com a atmosfera desponta uma geração, imbuída de uma nova sensibilidade estética e novos hábitos de consumo. Neste universo criou-se a base da primeira estrutura de mercado de arte no país, nas cidades de São Paulo e Rio de Janeiro, tendo como condutor as galerias privadas de arte moderna e comtemporânea.
\end{abstract}

Palavras-chave: Sociologia da cultura e da arte; mercado de arte; arte e cultura no Brasil; arte moderna e contemporânea; instituições artísticas, modernidade, mundialização.

\section{O mercado moderno: antecedentes}

Quando Paul-Durand Ruel decidiu, em 1870, orientar a política de sua galeria de arte em Paris para promover a obra dos impressionistas, inaugurou simultaneamente uma concepção de arte e uma forma de comercializá-la, ambas afinadas com o universo social de onde surgiram, a cultura urbana e a vida moderna. Instituiu um novo modus operanti - o mercado de arte moderna -, distinto tanto do acadêmico que o precedeu, quanto das diversas modalidades de comércio de arte que se desenvolveram a partir do século XIX (cf. Moulin, 1967; White, 1965; Bueno, 2001). Emerge um novo mundo da arte, evoluindo através de diferentes segmentos, pautados por

* Doutora em Ciências Sociais pelo IFCH-UNICAMP e pesquisadora na área de sociologia da arte, da cultura e da moda. É professora universitária e coordenadora do Mestrado Acadêmico em Moda, Cultura e Arte do Centro Universitário Senac em São Paulo.

Artigo recebido em 13 mai. 2005; aprovado em 8 ago. 2005. 
critérios e políticas distintas, como o mercado de arte antiga, o mercado de gêneros, o mercado de retratos, entre outros. No decorrer do século XX, este processo de segmentação aprofundou-se, revelando-se cada vez mais complexo.

Num ambiente atravessado por transformações constantes, os marchands de arte moderna caracterizam-se por sua associação com as novas visões de mundo, vendendo formas estéticas inovadoras. A escolha da posição influencia a direção das estratégias de mercado. O sistema moderno distingue-se do acadêmico anterior por configurarse como um mercado de autores e não de obras. Identificando-se com grupos e artistas e não com obras e estilos, o sucesso comercial do marchand está em investir em uma produção inovadora, que ainda não tem demanda, construindo um mercado para ela. $\mathrm{O}$ ponto de partida não é um público pré-existente, mas a obra de autores na contramão das modas correntes, que não tem ainda mercado.

A contemporaneidade é outro traço deste comércio, organizado em torno dos artistas vivos. A produção é selecionada e adquirida por suas qualidades simbólicas e intelectuais, que posteriormente convertem-se no fundamento do seu valor econômico.

A constituição de um mercado de arte moderna pressupõe a emergência social de alguns pré-requisitos. $\mathrm{O}$ primeiro está ligado ao nível de modernização da sociedade e ao estágio de consolidação da economia capitalista, uma vez que o desenvolvimento do mercado de arte, assim como do mercado financeiro, encontra-se associado ao volume de capital excedente disponível em circulação.

Outro pré-requisito é a presença de segmentos sociais novos, onde as identidades são elaboradas a partir de valores individuais, baseados na cultura e no consumo. O colecionismo, forte entre as elites urbanas no século XIX, teve uma função de reforçar socialmente a figura do colecionador e o seu poder, por meio do consumo ostentatório. Os museus domésticos foram criados a partir de objetos de luxo e obras consagradas, adquiridos nos leilões e antiquários. As 
relações entre colecionadores e artistas eram, geralmente, perpassadas pela dominação.

Já no mercado moderno as relações evoluem pontuadas pela admiração. Os colecionadores consomem imagens transgressoras como uma maneira de agregar valores intelectuais e inovadores, associados aos artistas, a suas vidas pessoais ou profissionais. Identificam-se com as visões de mundo dos artistas que colecionam, transformando esta prática em forma de expressão cultural. A existência deste segmento social pressupõe uma sociedade cosmopolita, onde o processo de distinção social não se realiza apenas pelo pertencimento a elites e grupos tradicionais locais, mas, cada vez mais, mediante estilos de vida construídos no fluxo da vida moderna. Vera Zolberg (1992) observa que as primeiras gerações de colecionadores de vanguarda foram formadas por indivíduos desterritorializados, com trajetórias à margem do mundo e dos valores das elites conservadoras locais.

Por fim, temos o caráter desterritorializado e internacional do mercado de arte moderna. No final do século XIX e início do XX, enquanto os primeiros marchands e artistas são europeus, geralmente sediados em Paris, a maior parcela do público comprador é estrangeira, sendo os norte-americanos o contingente mais representativo. Os franceses, muito tradicionalistas, mantém-se refratários às formas inovadoras até o final da Segunda Guerra Mundial. ${ }^{1}$

\section{O mercado de vanguarda em Nova Iorque}

Até 1940, o mercado moderno evoluiu focado na produção dos modernos europeus. Em Nova Iorque, desde os anos 1910, havia uma rede de galerias trabalhando com estes artistas. O comércio de arte contemporânea norte-americana era praticamente inexistente. Durante a Segunda Guerra, os museus e a crítica de arte novaiorquina vão traçar uma estratégia para promover os artistas de vanguarda atuantes na cidade. São pintores jovens, que articulam as suas referências estéticas a partir de um outro universo, apresentando propostas e posturas distintas dos europeus. ${ }^{2}$ 
A partir dessa geração, o mundo da arte moderna irá construir uma linha divisória, separando os consagrados, os modernos europeus, dos recém-chegados, as vanguardas contemporâneas. A manobra para promovê-los é bem sucedida, particularmente entre artistas e críticos. Mas o prestígio não se estende à esfera do mercado, que, após o final da guerra, permanece em torno dos europeus.

Peggy Guggenheim, em 1942, foi a primeira a trabalhar com os contemporâneos na cidade em sua galeria Art of this Century. Mas, só após 1945, identificamos a formação de um mercado para este segmento. Até o final dos anos 50, os principais pólos do mercado de vanguarda estavam em Paris e Nova Iorque. A centralidade exercida pelos franceses favoreceu a emergência de um núcleo de galerias em Paris, porém, foi em Nova Iorque que se constituiu uma estrutura para a arte contemporânea. Como os museus não forneciam suporte à vanguarda, sua promoção ficou a cargo das galerias privadas e da imprensa.

Nos primeiros tempos, até meados dos 50, os espaços operavam sem uma linha de conduta. Predominava um informalismo, com parte dos marchands priorizando o aspecto cultural em detrimento do mercadológico, enquanto outros para sobreviver, diversificavam, misturando contemporâneos com modernos. Num segundo momento, depois de 1957, o mercado começou a se profissionalizar em torno da vanguarda, com os marchands empenhados em viabilizar economicamente a tendência. Concretizaram a tarefa através de uma dupla atuação: no âmbito das instituições, conferindo legitimidade cultural às obras, e na esfera específica do mercado, transformando legitimidade em valor econômico.

Transformações na conjuntura econômica e social do mundo do Pós-Guerra viabilizaram esta operação. Inicialmente o aumento do volume de capital em circulação favoreceu a consolidação de novas fortunas. Estes novos ricos, como os armadores gregos e os artistas do star-system de Hollywood nos anos 50, investiram altas somas na aquisição de coleções impressionistas, pós-impressionistas e de modernos europeus. O aumento da demanda tornou as obras 
raras e os preços proibitivos, possibilitando a abertura de um canal para escoar a produção da nova geração.

Foi atuando através deste vácuo que o mercado de arte contemporânea se consolidou internacionalmente em torno da popart, e não do expressionismo abstrato, a origem deste processo. $\mathrm{Na}$ base deste sucesso comercial encontramos uma nova geração de colecionadores. São indivíduos que construíram seus negócios após a guerra, em setores recentes, quase sempre ligados à publicidade, aos meios de transporte e comunicações. Produtores de televisão, proprietários de agências de publicidade, redes de lojas e até de frotas de táxis, com estilos de vida sintonizados com processos culturais emergentes, estabeleceram uma sintonia imediata com a cultura visual dos artistas da pop-art.

\section{Campo artístico moderno no Brasil $^{3}$}

No Brasil, os anos 50 transitaram do nacionalismo de Vargas ao desenvolvimentismo de JK, passando pela implantação definitiva de uma sociedade urbana modernizada. Afinada com esta atmosfera, desponta uma geração imbuída de uma nova sensibilidade estética e novos hábitos de consumo.

Nesse universo formou-se a primeira estrutura de mercado de arte no País nas cidades de São Paulo e Rio de Janeiro, tendo como carro-chefe a arte moderna. Diferente dos norte-americanos, não havia entre nós galerias, instituições artísticas e, tampouco, um contingente de colecionadores de arte internacional. Foi apenas em 1947, através do Museu de Arte de São Paulo, o MASP, que tivemos a primeira coleção institucional importante de arte européia no País. Por outro lado, a base do mercado de arte em São Paulo e no Rio de Janeiro foi o comércio de arte moderna e contemporânea brasileira, revelando aproximações com a estrutura do comércio de vanguarda americana em Nova Iorque, no mesmo período.

No Brasil, o mercado de arte que se desenvolveu a partir do Pós-Guerra, apresenta singularidades que explicam a sua 
conformação nos anos 50 e 60, assim como muitos dos entraves que assinalam a evolução da arte contemporânea brasileira até nossos dias. Um dos objetivos desta explanação é fugir dos esquemas tradicionais que tendem a reduzir todos os nossos "insucessos" à condição periférica do país. Ao contrário, no campo da arte e da cultura, talvez ela venha ser o nosso diferencial. O Brasil, apesar das suas contradições, e muitas vezes por causa delas, dá um salto qualitativo no domínio cultural no período.

Somos um híbrido de tradições: arcaicas, emergentes e residuais. Mas qual modernidade não o é? Ao contrário dos europeus, entre nós os elementos emergentes predominam. Diferentemente dos norte-americanos, recebemos este processo com reservas. $\mathrm{O}$ rigor crítico da arte e da produção cultural brasileira do período frente ao provincianismo e conservadorismo das elites burguesas no País pode ser a chave para compreendermos tanto as limitações do nosso mundo da arte, quanto as dificuldades para viabilizar comercialmente a obra da vanguarda brasileira dos anos 1960.

A Segunda Guerra Mundial teve um impacto devastador, revolucionando o universo da arte e da cultura em escala planetária. Nesta circunstância histórica nasceram as bases da nossa sociedade globalizada. O Pré-Guerra e o Pós-Guerra acionaram uma desterritorialização de pessoas, idéias, imagens e modos de vida, numa dimensão até então inédita. A primeira estrutura de mercado de arte no Brasil foi resultado desse momento especial.

A maior parte dos galeristas e dos colecionadores de arte moderna no País, entre 1947 e o final da década de 1960, eram estrangeiros que aqui se fixaram por causa da guerra. Desempenharam um papel fundamental na construção dos fundamentos de uma cultura artística modernizada não só nas artes plásticas, mas também no teatro, no cinema, na televisão. Com relação aos artistas, foram estes recém-chegados que geraram as condições necessárias, para que, ao menos um segmento deles, pudesse sobreviver a partir da sua profissão. 
Mas se os colecionadores e galeristas eram quase todos recémchegados, a maioria dos artistas e críticos de arte eram brasileiros, ou imigrantes enraizados há muitos anos. À frente das instituições modernas - os museus e as bienais - temos uma burguesia industrial nacional, parte dela ligada aos meios de comunicações, financiando uma rede de arte moderna de fazer inveja a muitos países europeus. $\mathrm{Na}$ direção técnica dos espaços encontramos agentes culturais qualificados e com concepções avançadas, como crítico francês Leon Degand, trazido para o Brasil especialmente para ocupar a função.

Graças aos museus de arte moderna e às bienais, passamos a ter acesso à cultura artística internacional, sem precisar sair do País. Nas artes, registramos uma retomada das posturas vanguardistas e do diálogo com a produção internacional. Mas, tal como no início do século, predominava uma leitura acrítica do processo de modernização. Se os modernistas da Semana se alimentaram do sonho da modernidade, os concretistas viveram a ilusão da modernização.

Um perfil da produção artística em circulação no período contribui para compreendermos a maneira como foi apropriada pelo mercado. Nos anos 1950, a designação moderno, em São Paulo e no Rio de Janeiro, aplicava-se a uma obra que abarcava três segmentos de artistas relacionados com momentos diversos da história da modernidade das artes plásticas brasileiras. Os modernistas históricos da década de 1920, identificados com o núcleo da Semana de Arte Moderna de 1922, como Tarsila do Amaral, Anita Malfatti, Antonio Gomide, embora ainda atuantes, ocupavam uma posição secundária na vida artística.

A seguir, os artistas que despontaram entre 1930 e 1945, com propostas estéticas mais moderadas, prestigiados pela crítica de arte e pelo público comprador que começava a se formar na época. Foi ao redor deste grupo que se organizou a primeira estrutura de mercado de arte moderna no Brasil. Entre eles estavam as grandes estrelas da arte brasileira do período, como Cândido Portinari e Alberto da Veiga Guignard, além dos núcleos conhecidos como artistas operários, o Santa Helena, em São Paulo, e o Bernardelli, no Rio de Janeiro. 
Mas, outros da mesma geração, como Ismael Nery, permaneciam desconhecidos.

Finalmente, a vanguarda dos anos 50. Os concretistas, que agitaram a cena artística em São Paulo e no Rio de Janeiro, assinalam o início da arte contemporânea no Brasil, sendo os primeiros artistas a despontar num ambiente modernizado e sintonizado com o debate internacional. Críticos da cultura estética estabelecida, marcaram uma posição de ruptura em relação aos artistas dos períodos anteriores. Recebidos com reservas pelos colecionadores e pela crítica mais conservadora, ocuparam os museus e as bienais, encontrando respaldo entre intelectuais e críticos avançados, como Mário Pedrosa.

O período representou a autonomização da vida artística brasileira, quando apareceram instâncias de consagração propriamente modernas - como o Salão Nacional e a Bienal Internacional de São Paulo -, agentes especializados e locais de exposição fixos, como museus e galerias de arte. A constituição da rede de museus e bienais em São Paulo contou com o financiamento integral da burguesia local. No Rio de Janeiro, o Estado também participou do empreendimento. As elites brasileiras, como no início do século, viviam um complexo de sub-desenvolvimento, que procuravam superar cercando-se de arte e cultura. Nos anos 50 caracterizaram-se por uma ação mais ampla, extrapolando o espaço do mecenato dos salões privados, criaram museus, escolas, teatros - todo um equipamento para a difusão da cultura (Galvão, 1981). Para Maria Rita Galvão, o mecenato burguês do fim dos anos 40 adquire outra dimensão, uma vez que a valorização da cultura não tem mais uma função puramente aristocratizante, revelando um conteúdo de democratização.

O período de redemocratização do Pós-Guerra coincidiu com a prosperidade econômica e ativação do setor industrial. O processo de industrialização, ainda sem uma política própria conduzia-se através "de estímulos não intencionais - decorrentes de práticas cambiais processadas neste período" - já lançava os fundamentos do desenvolvimentismo da década de 50 (Lessa, 1982). A ampliação e a 
diversificação das camadas médias vão gerar um mercado consumidor atraente para a indústria cultural.

\section{Instâncias de consagração moderna criadas entre 1946 e 1952}

\begin{tabular}{|c|c|}
\hline 1947 & $\begin{array}{l}\text { MASP (Museu de Arte de São Paulo) } \\
\text { Iniciativa de Assis Chateaubriand (Diários Associados, Rádio \& TV Tupi) }\end{array}$ \\
\hline 1948 & $\begin{array}{l}\text { MAM-SP (Museu de Arte Moderna) } \\
\text { Iniciativa de Francisco Matarazzo Sobrinho (Industrial) }\end{array}$ \\
\hline 1949 & $\begin{array}{l}\text { MAM-RJ (Museu de Arte Moderna) } \\
\text { Iniciativa de Niomar Muniz Sodré Bittencourt (Correio da Manhã) }\end{array}$ \\
\hline 1951 & $\begin{array}{c}1^{\text {a }} \text { Bienal de São Paulo } \\
\text { Iniciativa de Francisco Matarazzo Sobrinho } \\
1^{\circ} \text { Salão Paulista de Arte Moderna }\end{array}$ \\
\hline 1952 & $\begin{array}{l}1^{\circ} \text { Salão Nacional de Arte Moderna (Rio de Janeiro) } \\
\text { Comissão Nacional de Belas Artes - MEC }\end{array}$ \\
\hline
\end{tabular}

Os museus de arte moderna converteram-se no principal espaço de exposição, legitimação e consagração dos artistas e das tendências plásticas da época, enquanto as bienais se projetaram como grandes pólos de informação e formação das correntes modernas internacionais. Os integrantes do movimento concreto revelaram uma orientação mais consciente em seus trabalhos, após o contato, em 1950, como a obra de Alexander Calder e Max Bill em exposições do MASP, e, em 1951, com a representação suíça na bienal.

Como produto da expansão das empresas jornalísticas - com estreita vinculação com as instituições que promoviam a arte moderna - a crítica de arte passou por um momento de desenvolvimento e profissionalização. Em 1949 é fundada em Paris a Associação Internacional de Críticos de Arte. Em 1951, coincidindo com o evento da $1^{\text {a }}$ Bienal, aconteceu em São Paulo o I Congresso Nacional de 
Críticos de Arte, no MASP, instalado no edifício dos Diários Associados. Foi o grande momento da crítica de arte brasileira.

No Rio de Janeiro despontou uma nova geração de críticos, articulada em torno de Mário Pedrosa, contrastando com a do período anterior, por suas posturas vanguardistas e intimidade com o universo das artes plásticas. ${ }^{4}$ Em São Paulo predominava a orientação crítica do período anterior, mais tradicional e conservadora. De acordo com depoimento de Mário Barata:

Foi com a geração de Mário Pedrosa e a minha que surgiu a especialização da crítica, de certa maneira já fora do domínio da literatura. Sérgio Milliet, Mário de Andrade ainda mais, porque atingia a criação, Aníbal Machado e Murilo Mendes mantinham a tradição do homem de cultura literária que se interessa pelas artes visuais. (...) é um problema geracional, um problema de época, de atuação de idade, que é muito importante. Geraldo Ferraz, Sérgio Milliet e Mário de Andrade conservaram-se mais ou menos ligados a uma expressão de arte como conteúdo humano e mesmo social. (Cochiarale \& Geiger, 1987, p. 115-116)

\section{Os primeiros anos do comércio de arte moderna ${ }^{5}$}

No comércio de arte temos a primeira iniciativa em $1947 \mathrm{com}$ a abertura da Galeria Domus, em São Paulo. Os proprietários, Ana Maria (Nina) Fiocca e seu marido, vieram da Itália no Pós-Guerra. ${ }^{6}$ De acordo com Nina Fiocca, o que os mobilizou foi uma curiosidade em relação à pintura brasileira contemporânea. ${ }^{7} \mathrm{O}$ espaço, ponto de encontro de europeus nostálgicos de um meio intelectual mais movimentado, virou referência na vida cultural da cidade, lugar de reunião de músicos, artistas, literatos e críticos de arte. Matérias, publicadas por ocasião da inauguração da Domus, denotam o provincianismo do meio paulistano, no final da década de 40:

Uma palavra ainda para aplaudir a iniciativa da galeria Doтиs e elogiarlhe a coragem de arriscar o patrocínio de exposições modernistas, bem pouco comerciais e por isso mesmo tão raras. Quando aludi à vitória do modernismo tinha em mente isso: a conquista das galerias 
e dos marchands. Essa conquista chega trinta anos depois das manifestações da Semana de 22, já vem tarde... tarde demais talvez, pois é bem possível que a época revolucionária tenha passado definitivamente e se caminhe agora para uma reação realista ou um decorativismo abstracionista ou, o que seria sem dúvida lamentável, uma arte dirigida de propaganda política. Entretanto, como vimos mantendo um bom atraso com o resto do mundo, o acontecimento não deixa de ser auspicioso. (Sérgio Milliet, O Estado de São Paulo, 16 jan. 1947)

O empreendimento manteve-se com dificuldades, fechando em 1953. A experiência deixou um lastro para a arte moderna em São Paulo. Os estrangeiros que freqüentavam o local, formaram o primeiro núcleo de colecionadores de arte brasileira contemporânea, e prosseguiram realizando aquisições no decorrer de toda a década de 50. Em 1958, Ernesto Wolff, um cliente assíduo da Domus, abriu a galeria São Luiz, convidando Nina Fiocca para dirigi-la.

\section{Arte e arquitetura moderna no Brasil}

A arte moderna brasileira ganhou um impulso a partir dos anos 30, com o desenvolvimento no interior do governo de Getúlio Vargas de uma política que privilegiava as formas estéticas inovadoras. Porém, é na arquitetura que os esforços do Estado se concentraram, sendo por meio dela que as artes plásticas obtiveram apoio oficial no período. Nos anos 1950 e 1960, em outro contexto político, os arquitetos modernos permaneceram em voga, através das propostas desenvolvimentistas do Governo JK, que tiveram na construção de Brasília o seu momento mais glorioso.

A primeira estrutura de mercado, nos anos 50, trás a marca desta condição histórica. Por vias diferentes, a arquitetura continuou exercendo uma liderança na consolidação do campo e do mercado moderno no País. Uma parcela do comércio de arte contemporânea nasceu da iniciativa de alguns arquitetos e designers de criar lojas de móveis modernos que, simultaneamente, operavam como galerias de arte. Encontramos também sintonias no domínio das vanguardas 
artísticas do período. Alguns dos concretistas, como Geraldo de Barros, trabalhavam como designers de móveis. Muitos artistas tinham formação universitária nas escolas de arquitetura, seguindo na esteira da antiga tradição da Escola Nacional de Belas Artes (ENBA), onde arte e arquitetura evoluíam lado a lado desde o início do século XX.

Até 1958-1959, os espaços de exposições comerciais, centrados na produção moderna, em São Paulo e no Rio de Janeiro, eram de caráter alternativo, Foram uma combinação de lojas de móveis modernos com galerias de arte, com a arquitetura moderna servindo de sustentação para as artes. $\mathrm{O}$ centro antigo paulista, na ocasião o coração da vida financeira e cultural da cidade, abrigou as primeiras galerias.

No Rio, elas se estabeleceram na Zona Sul, próximas a orla marítima, nos bairros de Copacabana e Ipanema, que concentravam a vida social da burguesia, o fluxo turístico e parte do comércio de luxo. No Distrito Federal, a vida mundana e artística mais intensa refletiu-se em um número mais elevado de locais de exposição. Ainda nos anos 40, apareceu a galeria Tenreiro, na esquina da Barata Ribeiro com Anita Garibaldi. Ali, Joaquim Tenreiro vendia sua produção de design e realizava exposições de seus amigos. A galeria Barcinsky na Rua Inhangá, em Copacabana, funcionava simultaneamente como loja de móveis, antiquário e galeria de arte. Na Praça General Osório ficava a Oca, numa loja de móveis modernos do arquiteto Sérgio Rodrigues. A Gea, do escultor Sérgio Camargo e de seu irmão, um paisagista, vendia móveis modernos, plantas e promovia exposições, como as de Heitor dos Prazeres e de Iberê Camargo. O Instituto Italiano mantinha também um espaço, a Piccola Galeria.

Mas, a mais importante foi a Petite Galerie, que reaparecerá em novos moldes, na estrutura de mercado da década seguinte. Criada no início dos anos 50 pelo escultor Mário Agostinelli, passou para as mãos de Franco Terranova por volta de 1952-1953. Desde o início, o marchand concentrou-se nos modernos. Embora também um misto de antiquário, galeria e loja de móveis, o setor artístico era muito ativo, transformando o espaço em centro de reuniões. 
Nos anos 50, já havia um mercado de bens de luxo em ascensão em torno de alguns leiloeiros, como Hernani, proprietário de uma casa na Ladeira da Glória. Comercializavam raridades, como peças do barroco brasileiro e pinturas de Elizeu Visconti e Castagneto. Organizou-se na ocasião um garimpo pelo interior do País, à cata de móveis antigos, estatuária barroca e objetos de arte popular. Muitos futuros marchands de arte contemporânea - como Fernando Millan e Jean Boghicci - estiveram envolvidos nesta coleta, conduzida tanto por interesses públicos, quanto privados. ${ }^{8}$

Em São Paulo, além da experiência da Domus, temos dois locais de exposição abertos na cidade no início dos anos 50: a galeria Ambiente e a galeria Tenreiro, ambas de caráter alternativo. Fundada em 1951 por Leo Seicman - futuro proprietário da Probjeto - a Ambiente foi mais uma combinação de loja de móveis modernos com galeria de arte. A Tenreiro, filial da loja do artista em Copacabana, tinha um projeto arrojado no Conjunto Nacional, na Avenida Paulista.

Tanto em São Paulo, como no Rio de Janeiro, a maioria dos espaços estava em mãos de arquitetos e designers modernos brasileiros ou de europeus que se fixaram no País no Pós-Guerra. Nestes locais - na década de 50 - as artes plásticas não conseguiram alcançar uma autonomia no mercado, comercializadas como elemento decorativo, ou complemento ideal de uma decoração moderna.

\section{As galerias de arte em São Paulo e no Rio de Janeiro}

Entre 1959 e 1964, organizou-se no eixo Rio-São Paulo, um mercado de galerias de arte moderna apoiado em bases mais profissionais. Restrito, somando pouco mais de meia dúzia de estabelecimentos entre as duas cidades, realizou uma classificação da produção não acadêmica até então, que serviu de substrato para uma construção da história da pintura moderna brasileira. A primeira versão, de Pietro Maria Bardi (1970), um dos agentes da nova 
estrutura de comercialização artística, foi editada pela Kosmos, cujo dono era proprietário de uma das galerias de arte paulistas, a Astréia.

\section{Galerias comerciais de 1958 a 1964}

\begin{tabular}{|c|c|c|}
\hline Ano & São Paulo & Rio de Janeiro \\
\hline 1958 & $\begin{array}{c}\text { GALERIA SÃO LUÍs } \\
\text { Nina Fiocca e Ernesto Wolff }\end{array}$ & \\
\hline 1959 & $\begin{array}{l}\text { GALERIAASTRÉIA } \\
\text { Stefano Gheiman }\end{array}$ & \\
\hline 1960 & & $\begin{array}{l}\text { GALERIA BONINO - Giovana Bonino } \\
\text { PETITE GALERIE - Franco Terranova }\end{array}$ \\
\hline 1961 & $\begin{array}{l}\text { ATRIUM } \\
\text { Emy Bonfim }\end{array}$ & RELEVO - Jean Boghicci \\
\hline 1962 & PETITE GALERIE & \\
\hline 1963 & $\begin{array}{l}\text { NOVAS TENDÊNCIAS } \\
\text { Artistas concretos }\end{array}$ & \\
\hline 1964 & $\begin{array}{l}\text { MIRANTE DAS ARTES - P. M. Bardi } \\
\text { SELEARTE - Giuseppe Baccaro }\end{array}$ & \\
\hline
\end{tabular}

À frente do mercado predominavam europeus, fixados em São Paulo e no Rio de Janeiro desde a Segunda Guerra. Alguns, como Pietro Maria Bardi e Giuseppe Baccaro, vieram para trabalhar como técnicos especializados na organização dos museus e das bienais de arte no início dos anos $50 .{ }^{9} \mathrm{O}$ núcleo de colecionadores responsável por um comércio regular era quase todo de estrangeiros de origem judaica. O quadro só se modificou na virada dos anos 70, com a consolidação do capitalismo no País, quando surgiu a figura do comprador de arte brasileiro.

No processo de formação da rede comercial apontamos dois perfis de galeristas. O primeiro, levado por uma conduta operacional espontânea, estava mais voltado para a valorização do caráter cultural e mundano de sua atividade. O segundo, já orientado por uma estratégia comercial, foi responsável pela criação do padrão de organização que estruturou o primeiro mercado de arte contemporânea brasileira. 
Na primeira categoria incluímos os paulistas que surgem entre 1958 e 1962. A cidade de São Paulo, em processo acelerado de crescimento urbano-industrial, permanecia com relação ao ambiente artístico mais atrasada e conservadora que a capital do País. Prevalecia um provincianismo entre a burguesia e os segmentos cultos paulistanos. O comércio de arte refletia esta atmosfera, evoluindo a reboque dos eventos sociais. Como nas galerias de vanguarda novaiorquinas dos anos 50, a necessidade de uma vivência cultural sobrepunha-se aos objetivos de ordem comercial, convertendo os espaços em locais de reunião puramente intelectual.

A intimidade anterior de alguns com o meio artístico, e a vontade de terem seus nomes ligados a empreendimentos desta ordem, mobilizou a abertura da maior parte das galerias: Gheiman, da Astréia, era proprietário da Livraria Kosmos e contava com numerosos artistas entre seus clientes; Emy Bonfim, casada com o poeta Paulo Bonfim, tinha como sócio um pintor do grupo Santa Helena, Clóvis Graciano; o marido de Giovana Bonino possuía uma galeria em Buenos Aires e Jean Boghicci era amigo dos artistas do movimento neoconcreto. Entre os empresários destacamos, Ernesto Wolff (Pratas Wolff) na São Luís, Tito Zarvos (Zarvos), na Atrium, José Carvalho (A Exposição e Clipper) na Petite Galerie. Se o capital que financiou a rede institucional vinha dos meios de comunicação, no caso das galerias de arte predominavam as empresas ligadas ao comércio.

Inexistia uma política de exposições, assim como não se levavam em consideração os critérios estéticos. Operavam com uma produção segmentada. No mesmo espaço conviviam múltiplas tendências: primitivos, figurativos regionalistas, abstracionistas informais, grupo Santa Helena, concretistas e neoconcretos. Não estavam empenhados em classificar a produção. De acordo com Stefano Gheiman, o que o levava a selecionar um artista era o nível de popularidade que seu nome havia alcançado.

Em São Paulo, vendiam-se, a preços médios, obras de artistas de renome, como os do Santa Helena e os abstratos japoneses. 
A partir desta ocasião todos eles abandonaram as atividades paralelas e passaram a viver exclusivamente da venda das obras. Ocasionalmente, organizavam exposições de uma ou outra estrela, como Di Cavalcanti ou Portinari.

As galerias trabalhavam em consignação, com uma comissão de $30 \%$, e não tinham a prática de adquirir trabalhos dos artistas. ${ }^{10}$ Pelas informações colhidas entre os marchands, o volume de aquisições era expressivo, ao menos até 1963. Havia um público comprador em ascensão e poucos espaços comerciais. Mesmo sem recorrer a uma estratégia de vendas, elas se efetivavam. ${ }^{11}$ Entre os compradores mencionados, estão sempre membros da comunidade israelita e alguns bancos ou firmas multinacionais.

Apesar deste dado, os galeristas, em seus testemunhos, pareciam empenhados em atender à demanda modesta da alta sociedade local. Como as artes plásticas eram um fato recente no seu universo, essas pessoas não haviam ainda incorporado um habitus que as levasse a valorizar a produção (cf. Bourdieu \& Darbel, 1969). Mesmo assim, os entrevistados manifestaram a preocupação recorrente de dispor de um acervo do agrado e com preços acessíveis a esta fatia de mercado. A Astréia chegou a contratar como relações públicas uma moça de família tradicional paulista; a Atrium promovia, nos finais de ano, feiras de Natal ${ }^{12}$ para vender obras de artistas conhecidos, em formatos menores e a preços módicos; e, Emy Bonfim solicitava, inclusive, aos artistas trabalhos especiais para atender aos caprichos desse consumidor, ainda ligado exclusivamente ao assunto:

Ciccillo comprava São Francisco, e Alcântara Machado, jacaré. Não teve um artista da época que não tinha pintado jacaré. E aquele, que era o dono do Yásigi, que foi muito pobre, gostava de caranguejo. Caranguejo, jacaré, mas não tinha um, todo mundo fez. (Emy Bonfim - depoimento)

Em São Paulo, o mercado despontou a partir deste núcleo de galerias que, alheias às práticas capitalistas, lembravam uma versão moderna dos salões da burguesia. Os primeiros marchands paulistas representaram uma resposta espontânea à demanda de consumo por 
arte brasileira contemporânea, que começou a emergir, no final dos anos 50, a partir da consolidação de uma sociedade de mercado. Já a reação dos cariocas foi mais consciente e organizada. Com um ambiente mais cosmopolita, de capital federal e centro turístico internacional, a ação ali foi orientada desde o início para a constituição de um mercado.

Em 1959, no MAM do Rio de Janeiro, aconteceu um leilão de arte beneficente, organizado pelo Jornal do Brasil, que foi um sucesso de vendas. As obras dos artistas brasileiros, do período de 30/40, alcançaram cifras elevadas, aguçando o interesse dos futuros marchands, para o potencial de mercado que havia ali.

Em 1960, Giovanna e Alfredo Bonino inauguraram, em Copacabana, a galeria Bonino, atuante até os anos 1980, a primeira no Rio a trabalhar exclusivamente com obras de arte:

Não havia mercado. Havia pessoas que compravam, os mecenas, que compravam diretamente do artista. $\mathrm{O}$ quadro não tinha um endereço certo. Havia algumas galerias, mas não exclusivas. (...) Tanto que, no começo, as pessoas que não conheciam bem diziam: "Mas vai vender só quadros, só esculturas, como é que vai viver?" (Giovanna Bonino, entrevista do arquivo pessoal de Maria Amélia Bulhões Garcia)

O foco principal era a obra dos artistas dos anos 30 e 40, "muito prestigiados na ocasião, como Volpi, Di Cavalcanti, Djanira, Portinari - todos artistas já consagrados, mas modernos". ${ }^{13}$ A mostra inaugural foi uma coletiva, reunindo modernos brasileiros e argentinos. O texto de apresentação do catálogo foi assinado por Mário Pedrosa. Muitos dos principais nomes foram contratados pela galeria, um sucesso de vendas.

No mesmo ano reabriu, em espaço especialmente projetado por Sergio Bernardes, a Petite Galerie. Permanecia à sua frente Franco Terranova, agora amparado pelo capital de José Carvalho, proprietário da Ducal. ${ }^{14} \mathrm{O}$ esquema era o mesmo da Bonino, grandes nomes da pintura brasileira, contratados pela galeria. A novidade foi a articulação de uma política de vendas. 
Reabertura da Petite Galerie do Rio com uma exposição de Guignard. A galeria, agora sob a responsabilidade de Sergio Bernardes, com a colaboração do Banco Sotto Maior, elaborou um plano de financiamento para a aquisição de obras de arte, com entrada de $20 \%$ e em 6 prestações com juros de $1 \%$ ao mês.(...). Quarenta artistas já assinaram contrato de financiamento com a Petite Galerie, entre eles: Manabu Mabe, Milton Dacosta, Maria Leontina, Mário Silésio, Rubem Valentin, Loio Pérsico, Glauco Rodrigues, Bianco e outros. (Revista Visão de Harry Laus, out. 1960, citado por Garcia, 1990, p. 131)

Tanto a Bonino, quanto a Petite - girando em torno da produção consagrada pelo público - faziam exposições com artistas de vanguarda, que mesmo sem aceitação comercial, agregavam uma legitimação cultural adquirida entre a crítica e as instituições. Em 1961 foi inaugurada a Galeria Relevo, de Jean Boghicci, em Copacapana. ${ }^{15}$ A partir daí, o mercado de arte brasileiro foi delineando o seu perfil.

Durante o período do Governo Goulart, com a aceleração do processo inflacionário e a desaceleração do crescimento econômico, um clima de instabilidade política, levou os investidores a procurar formas alternativas e mais seguras de aplicação de capital. No Rio, em 1962, havia um núcleo do mercado de arte organizando-se para captar parte destes investimentos. Na ocasião, morreram dois nomes de destaque da pintura moderna brasileira: Portinari e Guignard. Foi a primeira vez no Brasil que os preços de um artista subiram de quatro a cinco vezes, da noite para o dia. E o colecionador achou, então, que não podia perder tempo. Ampliou-se a demanda por arte moderna brasileira, enquanto os marchands consolidavam suas estratégias para enfrentarem o desafio.

A procura por uma produção moderna concentrou-se nos nomes consagrados, como Volpi e Di Cavalcanti que, nessa fase inicial de 1961-1962, eram todos contratados da Bonino ou da Petitte Galerie. Chegando atrasados nesta distribuição, Jean Boghicci e seus sócios buscaram outras saídas para atrair uma clientela: obras antigas dos grandes mestres. Colocavam pequenos anúncios nos jornais e quando apareciam os proprietários dos quadros compravam todos. 
Estenderam a atenção para modernistas, como Tarsila do Amaral então relativamente esquecidos -, e foram recolhendo os trabalhos mais antigos dos artistas que se encontravam espalhados.

Com o material coletado fizeram um catálogo de luxo com reproduções dos quadros, que enviavam pelo correio aos eventuais compradores.

A granfinada veio toda! Com decorador e tudo mais. A galeria pegou fogo nesse sentido, obras raras! Quem comprava eram empresários, médicos, engenheiros, cariocas e paulistas. Mas principalmente os judeus paulistas... (Jean Boghicci - depoimento para este trabalho)

Como revela o depoimento de Boghicci, começaram a articular uma política para reter as peças mais importantes, vendendo apenas o suficiente para alimentar o mercado sem inflacioná-lo.

O sistema de coleta da Relevo revelou-se mais lucrativo que o de contratos com os artistas, que foi sendo gradativamente abandonado. Permanecia em vigor uma política de aquisições com os artistas vivos e consagrados, enquanto com os jovens e os poucos conhecidos, operava-se na base de consignação. Já em 1963, Franco Terranova e José Carvalho se unem a Boghicci e Inimá Carneiro no garimpo por obras antigas dos modernos brasileiros. De São Paulo surgem mais duas adesões, Pietro Maria Bardi, diretor do MASP, e Giuseppe Baccaro. A maior parte do que ia sendo recolhido ficava guardada no acervo particular dos investidores, para posteriormente ser classificada. Personagens esquecidos como Ismael Nery, no ostracismo como Tarsila, Antônio Gomide e Anita Malfatti, foram resgatados nessa articulação, que seus agentes designavam como intercâmbio. Sobre a época, Baccaro observa que ajudou muito

... a falta quase absoluta de concorrência efetiva (...) No resto, todo mundo como eu, estava despreparado para a tarefa verdadeira. Eu tive apenas a vantagem de sacrificar mais horas de sono, coletar catálogos de velhas exposições, começar contatos com artistas pioneiros, como Antonio Gomide, Anita Malfatti que viviam esquecidos em seus ateliês. (...) No Rio, entrei em contato com a família de Portinari, e durante três ou quatro anos fui praticamente o 
único a trazer sua obra para São Paulo. Claro que Portinari era muito conhecido, mas por outras razões que não a obra. (Giuseppe Baccaro, 1973)

Em 1964, os paulistas, inicialmente associados, separam-se, abrindo suas próprias galerias. A de Bardi, o Mirante das Artes, era um escritório de arte, um ponto para comercialização da produção estocada. Para a agitação cultural - necessária para a promoção do acervo - recorria à estrutura do Museu de onde era diretor.

Baccaro fundou a Selearte, que, em 1967, transformou-se na primeira casa de leilões a trabalhar com os modernos. ${ }^{16}$ Mônica Filgueiras de Almeida - que já possuía uma intimidade com as artes, adquirida na atividade de monitora da Bienal de São Paulo - foi contratada para ajudar a selecionar o material recolhido.

Quando comecei a trabalhar com Baccaro, os modernistas não eram mais proprietários de sua produção; ela já se encontrava toda na mão dos marchands. Na casa de Baccaro já estava estocada toda a história da arte brasileira (moderna). Sabia-se que estava lidando com uma produção cultural e histórica importante. Essas pessoas tinham uma formação cultural muito sofisticada e trabalhavam com obras de artistas completamente desconhecidos: como o acervo de Gomide e de Ismael Nery, que Baccaro juntou e que, até então, ninguém tinha conhecimento deles.

Baccaro tinha uma sala com uma mesona . Ele ia abrindo as gavetas e jogando os trabalhos em cima. Depois me mandava separar guache, de aquarela, de têmpera, de nanquim e de técnica mista. Eu fazia pilhas das coisas, quando estavam prontas me fazia separar Di Cavalcanti, de Tarsila, de Gomide, de Ismael Nery... Eu não sabia nada. Estava vendo a maioria daqueles nomes praticamente pela primeira vez na minha vida, não tinha um livro ou um curso para estudar História da Arte Brasileira. Eu aprendi ali. (Mônica Filgueiras de Almeida - depoimento para este trabalho)

Os artistas que ainda estavam vivos, todos muito velhos e passando por dificuldades financeiras, perderam completamente o controle sobre sua produção.

"Fiz uma exposição de Gomide em minha galeria (a Selearte). (...)Tarsila, eu conheci mais ou menos em 65. Bati à sua porta, 
encontrei seu sorriso de alma adolescente no corpo já perdido. Andei vendendo com bom lucro. Tarsila me ajudou muito naquela subida. $\mathrm{E}$ isso devo dizê-lo, reanimou bastante esses artistas. Para Gomide, enviei toras de cedro, que ele começou a esculpir. Para Tarsila mandava preparar telas e comprava tintas Lê Franc em Paris. São dessa época seus últimos trabalhos de nível, nos quais correu ainda milagrosamente a seiva do "pau-brasil. (Baccaro, 1973)

Um exemplo da estratégia foi a organizada em torno da obra de Ismael Nery. Mário Pedrosa e Murilo Mendes foram os primeiros a alertar o grupo para a obra do artista, tido então como maldito. A partir daí começou o garimpo. Para Baccaro, seu

mérito foi apenas reunir suas obras, quando ainda nem sabia direito quem ele era. A sigla I/N começou a me parecer a chave de uma nova terra prometida na arte brasileira. (Baccaro, 1973)

A articulação foi um sucesso. Em 1965, na VIII Bienal de São Paulo, havia uma sala especial com a obra surrealista de Nery. No ano seguinte, a exposição foi para o Museu de Arte Moderna do Rio de Janeiro. Na mesma ocasião na Petite Galerie acontecia uma outra mostra do pintor. Todos os eventos receberam ampla cobertura da imprensa (Bento, 1973).

\section{O modelo de mercado}

Estruturando-se como um comércio de bens de luxo, em torno de artigos raros e, por isso, caros, o mercado de arte brasileiro orientouse para uma estratégia de leilões, o caminho natural para o escoamento deste tipo de produção. ${ }^{17}$ Em meados da década de 1970 a maior parte da obra dos modernos brasileiros, assim como a dos acadêmicos, estava fora do alcance do público, na casa dos colecionadores particulares. O sistema de leilões entrou, então, em declínio e as pequenas galerias voltaram a dar o tom no mercado.

Os dois tipos de galeristas aqui enfocados orientaram-se para suprir uma demanda pré-existente na clientela, de preencher com o consumo de arte necessidades de decoração e ostentação. Os 
primeiros paulistas, de forma mais espontânea, o fizeram reunindo em torno de si os artistas mais procurados. Os segundos, já movidos por uma lógica de mercado, adotaram o procedimento dos antiquários: localizaram uma produção antiga e esquecida, a obra dos modernistas, que adquiriram a preços muito baixos e estocaram; a seguir, foram construindo uma história da pintura brasileira em torno do material que manipulavam. Com esta operação transformaram um produto sem valor comercial em artigo de alto luxo e, neste movimento, recorreram à infra-estrutura dos museus e ao sistema de leilões para viabilizá-la comercialmente.

No Brasil, o mundo da arte contemporânea evoluiu reproduzindo o modelo internacional, mas operando apenas em âmbito nacional. $\mathrm{O}$ mercado consolidou-se usando a produção contemporânea como fachada, mas realizando-se comercialmente através da venda dos grandes nomes do modernismo brasileiro, fundados principalmente no eixo Rio-São Paulo e que evoluíram em torno da arte local e de uma clientela também local.

Na década de 1970, permaneceu em vigor o mesmo modelo. A produção contemporânea foi encontrando seu espaço num circuito comercial precário e altamente competitivo, onde a oferta era sempre superior à demanda. As galerias especializadas continuavam subsistindo economicamente recorrendo à estratégia dos anos 60: nas vitrines e eventos promoviam a arte corrente, mas os lucros vinham das vendas de grandes nomes do modernismo brasileiro realizadas nos bastidores. ${ }^{18}$

\section{Notas}

1 Foi somente em 1947 que foi inaugurado o Museu de Arte Moderna da cidade de Paris, a primeira instituição no gênero na França. A exposição inaugural foi em torno dos fauvistas e dos cubistas, consagrados entre os colecionadores internacionais e também pelos museus norteamericanos nos anos 1930.

2 Sobre o mercado de vanguarda em Nova Iorque, consultar: Crane (1987), Bynstryn (1948); Crow (1996), Guilbaut (1992), Bueno (2001). 
3 Sobre o campo artístico moderno no Brasil, ver: Arruda (2001), Durand (1989) e Bueno (no prelo).

4 Ferreira Goulart, responsável pela coluna do Jornal do Brasil, foi um dos articuladores do neoconcretismo carioca. Jaime Maurício, do Correio da Manhã, foi aluno de Guignard e marcou uma presença regular nos júris de seleção das Bienais Internacionais. No Diário de Notícias estava Mário Barata, no Diário Carioca, Antonio Bento e na Tribuna da Imprensa, Mário Pedrosa.

5 Sobre o início do comercio de arte moderna no Brasil, ver: Durand (1989) e Bueno (no prelo).

6 Eram ligados aos industriais de origem italiana, como os Matarazzo, e ao grupo de intelectuais que girava em torno de Pietro Maria Bardi. Montaram uma indústria de tecelagem e em seguida a galeria de arte.

7 De acordo com depoimento de Ana Maria Fiocca para este trabalho, em janeiro de 1987.

8 "Quando Jânio Quadros foi eleito, Mário Pedrosa ficou chefe de cultura e Ferreira Gullar trabalhava na Fundação Cultural de Brasília. Eles chamaram a mim e o José Carlos de Oliveira para colher material de arte popular pelo Brasil inteiro. Ele foi para o Sul e eu, para o Norte. Por três meses andei de avião, de jipe, de teco-teco... Recolhi 44 caixotes! Tudo que hoje faria o fervor de muito colecionador de ex-votos" (J. Boghicci, entrevista concedida à autora em julho de 1989).

9 Bardi veio ao Brasil após a guerra e logo integrando até hoje o corpo do MASP como diretor. Baccaro chegou nos anos 50, para trabalhar na organização das bienais.

10 Segundo Emy Bonfim, "As vezes a gente fazia uma aquisição mais para ajudar o artista - 1 ou 2 quadros. Era muito mais humano. Hoje não me adaptaria. Todos eles ficam ricos. Não pode ser com os 30\% que ganham com os artistas. São as negociatas. Hoje tem que se ter capital”.

11 "No início vendia muito, depois aumentou a concorrência e se dividiu mais o mercado. Foi o mesmo com os livros de arte. No início a Kosmos era a única" (S. Gheiman).

12 "Nas feiras, o Zanini, por exemplo, mandava 300, 400 trabalhos. Eu tinha vergonha de devolver o que sobrava. Todo mundo comprava porque era barato. E eu conhecia todo mundo. Quando vinha gente de outras galerias eu não vendia. Os artistas que vendiam obras por 150 mil réis, tinham na feira trabalhos por 3 mil.”(E. Bonfim). 
13 Giovanna Bonino, entrevista do arquivo pessoal de Maria Amélia Bulhões Garcia.

14 A Ducal era uma rede de lojas especializada em vestuário masculino.

15 A abertura foi com uma exposição de Emeric Marcier, outro artista que se projetou nos anos 40 . O marchand contava também com o apoio de financistas.

16 A Selearte foi a segunda a funcionar nos moldes de uma empresa capitalista moderna em São Paulo - a primeira foi uma filial da Petite aberta na Aveninda Paulista, em 1962.

17 Baccaro em 1967 foi o primeiro a tomar a direção. Foi seguido pela Petite Galerie e pela Bolsa de Arte do Rio de Janeiro de Inimá Carneiro, outro membro do intercâmbio. A Collection, de José Paulo Domingues, abre na ocasião adotando a mesma prática comercial.

18 Ao contrário do que ocorreu no mercado internacional são os artistas que fornecem prestígio às galerias, numa conjuntura similar à do mercado dos expressionistas abstratos em Nova Iorque, revelando um universo comercial ainda frágil. Ver: Byrstryn (1948) e Guilbaut (1992).

Abstract: The gallery market and commerce of modern art: São Paulo and Rio de Janeiro in the 1950's-1960's.

In Brazil, the 1950's from the nationalism of Vargas to the developmentism of JK, passing through the definitive implantation of a modernized urban society. Tuned with the atmosphere, a generation is born, impregnated with a new habit of consumption. In this universe, the basis for the first structure of art market in the country was created in the cities of São Paulo and Rio de Janeiro, having as conductores the private galleries of modern and contemporary art.

Key words: sociology of culture and art; art and cuture in Brazil; modern and contemporary art; art institutions, modernity, globalization. 


\section{Referências bibliografia}

ARRUDA, Maria Arminda do Nascimento. Metrópole e cultura: São Paulo no meio do século XX. Bauru: EDUSC, 2001.

BACCARO, Giuseppe. Que eles se estrepem! Entrevista a Olívio Tavares de Araújo. Revista Veja, 18, 18 mar. 1973

BARDI, Pietro Maria. Profile of the New Brasilian Art. São Paulo: Kosmos, 1970.

BENTO, Antônio. Ismael Nery. São Paulo: Gráficos Brunner, 1973.

BOURDIEU, Pierre; DARBEL, Alain. L'amour de l'art. Paris: Minuit, 1969.

BUENO, Maria Lucia. Artes plásticas no século XX: modernidade e globalização. São Paulo: Editora da Unicamp, Imesp, Fapesp, 2001.

BUENO, Maria Lucia. Modernidade à brasileira: artes plásticas em São Paulo e no Rio de Janeiro. São Paulo: Editora do Senac, [no prelo].

BYNSTRYN, Marcia. Art galleries as gatekeepers: the case of the abstract expressionists. Social Research, n. 45, summer, 1948.

COCHIARALE, Fernando; GEIGER, Anna Bella. Abstracionismo geométrico e informal: a vanguarda brasileira nos anos cinqüenta. Rio de Janeiro: Funarte, 1987.

CRANE, Diana. The transformation of the avant-garde: the New York art world -1940-1985. Chicago: University of Chicago Press, 1987.

CROW, Thomas. Modern art in common culture. New Haven: Yale University Press, 1996.

DURAND, José Carlos Arte, privilégio e distinção. São Paulo: Perspectiva, 1989.

GALVÃO, Maria Rita. Burguesia e cinema: o caso Vera Cruz. Rio de Janeiro: Civilização Brasileira, 1981.

GARCIA, Maria Amélia Bulhões. Artes plásticas: participação e distinção - Brasil 60/70. São Paulo, 1990. Tese (Doutorado) - FFLCH/USP.

GUILBAUT, Serge. Le marketing de l' expressivité a New York au cours des annés cinquante. In: BERTRAND-DORLÉAC, Laurence (Dir.) Le commerce de l' art: de la Renaissance à nos jours. Besançon: La Manufacture, 1992. 
LESSA, Carlos. 15 anos de política econômica. São Paulo: Brasiliense, 1982.

MOULIN, Raymonde. Le marche de peinture en France. Paris: Minuit, 1967.

WHITE, Harrison C.; WHITE, Cynthia A. Canvases and careers: institutional change in the French painting world. New York: John Wiley, 1965.

ZOLBERG, Vera. Une marginalité creatice: les collectionneurs de l'art d'avant garde. In: MAJASTRE, J.-O.; PESSIN, A. (Dir.). Art et contemporanéité: premières rencontres internationales de sociologie de l'art de Grenoble. Bruxelas: La Lettre Volée, 1992. 